\title{
VIII
}

\section{GUERRA ÀS DROGAS EM CONTEXTO DE PANDEMIA: REPERCUSSÕES NA SAÚDE MENTAL DAS MULHERES NEGRAS ${ }^{*}$}

Daniela Ferrugem Beatriz Gershenson

\section{Introdução}

As mulheres negras são a base da pirâmide da sociedade capitalista, são elas as mais exploradas, e as que mais lutam para romper as barreiras impostas pelo racismo e sexismo, que insistem em tornálas invisíveis. É uma invisibilidade que as atinge desde sua existência nas periferias e se estende aos seus esforços de inserção na academia. A classe social não as protege. A intersecção entre o racismo, o sexismo e o ódio de classe que atingem as mulheres negras podem assumir variadas formas, tornando a vida de uma mulher que vive na periferia uma experiência diferente de uma intelectual negra, mas ambas não escapam ao racismo e às investidas cotidianas de extermínio do capitalismo, que inclusive atua de forma simbólica, que é parte e expressão das estratégias de acumulação infinita do capital em uma ordem social em que as desigualdades são banalizadas e consideradas inexoráveis, mesmo pelo senso comum.

São expressões de violência que passam pela morte física, mas também pela tentativa de apagamento da potência de vida, ou seja, pela morte social das mulheres negras, já conceituada no campo da bioética como mistanásia (FERREIRA; PORTO, 2019), a morte precoce e evitável, referida à violência estrutural, aquela que "é embutida na estrutura e aparece como desigualdade de poder e consequentemente como chances desiguais de vida" (GALTUNG, 1969, p. 171, tradução nossa). A mistanásia, assim, está associada à ação ou omis-

*DOI- 10.29388/978-65-86678-44-4-0-f.203-224 
são do Estado que é responsável pela manutenção da pobreza, pelas chacinas promovidas através dos aparatos de controle social, pela seletividade penal (GERSHENSON et. al, 2017) e perpetuação de violações de direitos que retiram da população as condições mínimas para uma vida digna de ser vivida.

Tratam-se de mortes que se conectam ao descaso diante da vida de pessoas cuja existência parece não importar, ou melhor dizendo, são expressões concretas da hierarquização racial, de gênero e de classe sobre a qual assenta a ordem do capital, que ergue como natural um ideal abstrato de humanidade em que alguns são considerados mais humanos que outros, não sendo as vidas dos menos humanos, quando roubadas, sequer passíveis de serem pranteadas, uma vez que são vidas que não importam (BUTLER, 2011).

Angela Davis (2018) nos alerta sobre a racialização e generificação desta visão, que apenas na aparência, corresponde a um "ser humano" abstrato porque universal - pois, em verdade, este ideal universal tem como referência o gênero masculino e a cor branca. Seguindo o pensamento da autora, se de fato todas as vidas humanas importassem, por que haveria a necessidade de argumentar-se que "vidas negras importam"?

Para a autora, é fundamental reconhecer-se a importância de esforços teóricos e práticos, como o feminismo negro, que contribuam para "demonstrar que raça, gênero e classe são inseparáveis nos contextos sociais em que vivemos" (DAVIS, 2018, p. 21). Embora a emergência destes esforços não sejam novidade, já que os primeiros escritos a respeito datam da década de 1980, ainda hoje negamos esta inseparabilidade. Negamos também a discriminação racial e seus efeitos, que já no final da década de 1970 o movimento negro unificado em uma manifestação histórica denunciava:

Hoje, estamos nas ruas numa Campanha de denúncia!

Campanha contra a discriminação racial, contra a opressão policial, contra o desemprego, o subemprego e a marginalização. Estamos nas ruas para denunciar as péssimas condições de vida da Comunidade Negra. Hoje é um dia histórico. Um novo dia começa a surgir para o negro! (HASENBALG; GONZALEZ, 1982, p. 50). 
O trecho citado é parte da carta denúncia lançada no dia 07 de julho de 1978, nas escadarias do Teatro Municipal de São Paulo, dia que segue como marco de criação do Movimento Unificado Contra a Discriminação Racial hoje conhecido como Movimento Negro Unificado - MNU. Nesta carta já estava presente a preocupação com a violência policial e as condições de vida dos negros e negras. Quatro décadas separam estas denúncias de violência do momento atual. O mais grave é que tais denúncias seguem sendo urgentes e necessárias, pois as violências que reportam não só persistem como também se acirram. Realidade agravada pela pandemia do COVID-19, que causou uma crise sanitária e social globalizada iniciada na China em dezembro de 2019, mas começou a dar sinais no Brasil no mês de março. No país, a negligência como projeto de governo agravou em muito a situação, ampliando o fosso da desigualdade racial e social. A falta de uma coordenação sanitária nacional fez com que as respostas dadas pelos municípios e estados fossem bastante diferentes entre as regiões do país, castigando de maneira particular as regiões mais pobres do país, e atingindo com maior letalidade os negros e negras, que vivem em maioria nestas regiões.

Guerra às drogas e pandemia se entrecruzam, e demonstra de maneira irrefutável que está em curso, ainda, um genocídio da população negra, como já alertava Abdias Nascimento (2017).

\section{Guerra às drogas em tempos de pandemia}

Em muitas sociedades e em diferentes momentos históricos, os humanos fizeram uso de substâncias psicoativas, buscando alcançar diferentes objetivos, com usos ritualísticos, festivos, alimentícios, terapêuticos ou em busca de sensações de prazer (ESCOHOTADO 2008; CARNEIRO, 2002). Muitos estudos investigam os vestígios deste uso, onde:

[...] do ponto de vista do campo de estudos da cultura e da política, no seu sentido mais amplo, a existência e o uso de substâncias que promovem alterações na percepção, no humor e no sentimento são uma constante na humanidade, remontando a lugares longínquos e a tempos imemoriais (SIMÕES, 2008). 
No entanto, a solidificação do consumo e do mercado de drogas ocorreu no século XX. Desde então, o mercado global para consumo de drogas só cresce, assim como o lucro gerado pelo comércio ilegal, ainda que o estatuto proibicionista tenha se acirrado e intensificado o combate bélico contra o comércio das substâncias, numa escalada global de guerra às drogas. Trata-se da defesa de um modelo político, econômico e social ancorado na falsa premissa de uma sociedade sem drogas, mas baseado desde o princípio no racismo, xenofobia, puritanismo e interesses financeiros. Ainda hoje a proibição das drogas atende a interesses moralizantes, mas também políticos e econômicos.

O racismo está na base da proibição das drogas no Brasil, sendo que a primeira legislação proibitiva no Brasil data de 1932 e proíbe o consumo da maconha. Os discursos conservadores, nas teorias raciais eugênicas, relacionavam aos negros o consumo de drogas, criando um clima de ojeriza a costumes vistos como sem civilidade e obstáculo para o projeto dominante de uma sociedade "avançada" e, portanto, embranquecida. Como refere a pesquisa de Saad:

Nesse cenário, o que representasse uma herança africana ou a resistência ao embranquecimento deveria ser extinto. O uso da maconha era associado à prática do candomblé e vice-versa (...). Ambos iam na contramão do progresso tão sonhado pelas elites. Curandeiros, feiticeiros e maconheiros ameaçavam o projeto de um futuro brilhante para o país (SAAD, 2013, p. 12).

As teorias eugênicas foram refutadas, mas o discurso racista presente nestas teorias raciais segue vigente na sociedade brasileira. A hierarquia racial proposta nesta época segue operando por meio do racismo, no qual "o corpo escravizado desaparece, mas o corpo negro permanece, transmutando-se em sinônimo de gente pobre, sinônimo de criminalidade e um ponto de inflamação nas políticas públicas" (MORRISON, 2019, p. 08).

A hierarquia racial que serviu para a escravidão dos povos africanos nas Américas, segue operando por meio do racismo. "Nesse racismo, o corpo escravizado desaparece, mas o corpo negro permanece, transmutando-se em sinônimo de gente pobre, sinônimo de criminalidade e um ponto de inflamação nas políticas públicas" 
(MORRISON, 2019, p. 08). É este corpo negro que tem sido vitimado em maior medida no contexto de pandemia. Uma pesquisa que foi veiculada em vários portais de notícia revela que "dos 8.963 pacientes negros internados, 54,8\% morreram nos hospitais. Entre os 9.988 brancos, a taxa de letalidade foi de 37,9\%" (BATISTA et al, 2020, p. 4). É emblemático que a primeira morte registrada por COVID-19 tenha sido de uma mulher negra, que trabalhava como doméstica e não teve direito ao cuidado e isolamento, preconizado pelos organismos de saúde internacionais e nacionais, já que a mulher negra é o perfil mais vulnerável ao COVID-19. Em levantamento feito pelo Instituto Brasileiro de Geografia e Estatística (IBGE) em junho, 57,8\% das pessoas que disseram ter contraído mais de um sintoma da doença eram mulheres, contra $42,2 \%$ de homens (IBGE, 2020). Mais de um sintoma associado pode refletir numa piora no quadro geral de saúde da pessoa. Além de serem as mulheres as mais afetadas pelo desemprego e serem socialmente responsabilizadas pelo cuidado de filhos e/ou parentes doentes.

Essa hierarquia também opera a partir da guerra às drogas, que no Brasil sempre esteve na sinergia entre raça, classe e gênero sua estruturação e, encontrando neste país de pensamento colonial persistente terreno fértil para a proibição das drogas, adota o estatuto proibicionista estadunidense. A proibição das drogas, sob o pretexto de proteção à saúde das pessoas, e o enfrentamento do comércio das substâncias, têm servido como medida para a manutenção da hierarquia racial, segundo Hart,

\footnotetext{
O foco quase exclusivo nos efeitos negativos também colaborou para uma situação em que deparamos com a meta indesejável e irrealista de eliminar certos tipos de consumo a qualquer custo. Com demasiada frequência o preço é pago sobretudo por grupos marginalizados (HART, 2014, p. 293).
}

O pesquisador refere-se à realidade das cidades estadunidenses e suas periferias por ele observadas, mas podemos transpor para a realidade brasileira considerando ainda que temos grandes áreas periféricas, territórios vulnerabilizados onde a política pública mais presente costuma ser a de segurança pública, em contraste com a ausência de políticas de moradia, trabalho e renda, e por vezes saúde. 
Nestes territórios periféricos a violência é prática sistemática do Estado, mesmo em contexto de calamidade pública por uma pandemia, o Estado não cessou as operações policiais de combate ao comércio ilegal de drogas, ao contrário, em vez de alocar toda a estrutura estatal mobilizada para proteger a saúde das pessoas intensificou as operações no Rio de Janeiro.

Além de não prover cuidado em saúde ampliando atendimento, fornecendo informações objetivas e verdadeiras de acordo com as orientações sanitárias, kits de higiene e renda mínima, negligencia estes direitos básicos e impede as alternativas solidárias construídas por moradores e organizações não governamentais de acontecerem ao intensificar as operações policiais, inclusive com disparos em meio à distribuição de cestas básicas, como ocorreu no Rio de Janeiro. Segundo noticiado pelo jornal El País, entre os "[...]meses de março e abril, 290 pessoas morreram no Estado em operações policiais, embora parte da população estivesse confinada em casa por recomendação das autoridades e os crimes em geral tenham diminuído" (GORTÁZAR, 2020).

Número superior ao mesmo período do ano de 2019. Além das mortes por operações policiais, os conflitos armados cotidianos, a guerra às drogas também produz o encarceramento de jovens e muIheres negras. Ainda de acordo com Hart, "O custo humano dessa abordagem equivocada é incalculável, pois centenas de milhares de homens e mulheres, inclusive membros de minha família, estão na prisão por causa disso" (2014, p. 293). A guerra às drogas encarcera milhares de pessoas no mundo. No ano de 2006 o Brasil tinha 170 mil pessoas encarceradas, já no ano de 2017 a população carcerária mais do que quadruplicou, aumentando para 727 mil pessoas, assumindo assim um vergonhoso pódio com a terceira maior população carcerária do mundo. Segundo reportagem da Ponte Jornalismo, o número de pessoas encarceradas aumentou de 727 mil pessoas, quando alcançou a terceira posição, para 812 mil pessoas entre regime fechado, semiaberto e quem cumpre pena em abrigos, até 2019. Este número pode ser maior à medida que há uma demora para atualização dos dados pelos Estados (VASCONCELOS, 2019).

A situação das mulheres encarceradas é ainda mais preocupante, visto que houve um crescimento exponencial no encarcera- 
mento. Dados do Levantamento Nacional de Informações Penitenciárias (INFOPEN) indicam que "A população penitenciária feminina no Brasil apresentou crescimento de 567,4\% entre 2000 e 2014 . No ano de 2016 a população feminina encarcerada era de 42.355 mulheres (BRASIL, 2018). Se considerarmos a população carcerária a partir do gênero o país ocupava o 4ㅇ lugar mundial em mulheres encarceradas em números absolutos. No entanto, se analisarmos a taxa de aprisionamento em comparação a outros países, o Brasil tem uma taxa 40.6 mulheres presas por 100 mil habitantes, passando à frente da Rússia (3ㅇ lugar em número absoluto de mulheres encarceradas), que tem uma taxa de por 33,5 mulheres encarceradas por 100 mil habitantes, e da China (2o lugar em números absolutos), cuja taxa é de 7,6 muIheres presas por 100 mil habitantes (BRASIL, 2018, p. 13).

É importante refletirmos a partir da taxa de encarceramento, pois possibilita uma análise mais aproximada da realidade, onde temos a segunda maior população feminina encarcerada proporcionalmente à população total do país. Isso se deu a partir de um crescimento acelerado, já que

Em Junho de 2016, a população prisional feminina atingiu a marca de 42 mil mulheres privadas de liberdade, o que representa um aumento de $656 \%$ em relação ao total registrado no início dos anos 2000 , quando menos de 6 mil mulheres se encontravam no sistema prisional (BRASIL, p. 14, 2018).

Deste contingente populacional de brasileiras no cárcere, ainda de acordo com INFOPEN, 45\% das mulheres presas no Brasil em junho de 2016 não haviam sido ainda julgadas e condenadas, são presas provisórias. Esta parcela correspondia a 30,1\% das mulheres encarceradas em junho de 2014 (2018, p. 19).

Quem são estas mulheres? Cerca de $89 \%$ delas têm entre $18 \mathrm{e}$ 40 anos, sendo $50 \%$ jovens de até 29 anos (BRASIL, 2018, p. 37). Do total, $62 \%$ destas mulheres são negras, o que atesta a seletividade do sistema penal. Podemos inferir que este dado não é exato, já que, em razão do racismo estrutural, temos uma grande dificuldade para a coleta deste dado, uma vez que o critério raça/cor é negligenciado no momento do preenchimento de documentos nas políticas sociais, incluindo o sistema penitenciário. A grande maioria, 74\% das mulheres 
privadas de liberdade, têm filhos (BRASIL, 2018, p. 51), dado que se refere ao percentual de mulheres sobre as quais foi possível o sistema penitenciário resgatar esta informação. Seja como for, é possível inferir que muitas crianças são impactadas pelo encarceramento em massa.

Portanto, estas jovens mães e negras são as mulheres que sofrem com o encarceramento em massa (BORGES, 2018), e a guerra às drogas é um importante propulsor para este encarceramento, já que os crimes relacionados ao tráfico de drogas correspondem a $62 \%$ das incidências penais pelas quais as mulheres privadas de liberdade foram condenadas ou aguardam julgamento em 2016" (BRASIL, 2018, p. 53). Isso significa que "que 3 em cada 5 mulheres que se encontram no sistema prisional respondem por crimes ligados ao tráfico" (idem).

Neste sentido a mulher negra tem sido um alvo da guerra às drogas, sofrendo duplamente os efeitos pelo encarceramento em massa: tanto por ter que se responsabilizar sozinha pela família e fiIhos no caso do encarceramento do companheiro, além de ser responsável por mantê-lo no sistema prisional, que por ter péssimas condições e dinâmicas que favorecem a organização em grupos e guerra por domínio do espaço, exigem que as famílias arquem com alimentação, roupas, entre outros itens para se manter o ente em relativa segurança; quanto por ver-se ela própria em situação de prisão e cárcere. Novamente se vê como alvo da guerra às drogas quando tem que chorar a morte de um filho pela violência das disputas de territórios, das abordagens da segurança pública, dos conflitos armados.

Tanto o encarceramento como a morte dos jovens negros, que são 77\% dos jovens assassinados no Brasil, caracterizando genocídio da juventude negra (WERNECK, 2020), tem a capacidade de provocar mortes, como cessão da vida de forma objetiva e simbólica, ao produzir o medo da morte, mas também as ausências, o luto e a negação do direito à memória, que de maneira objetiva impacta a vida de comunidades inteiras (FERRUGEM, 2019). Assim, é para além do genocídio como estritamente a morte da população negra: é o genocídio também como morte presente em vida. 
Neste contexto, a ausência de apoio e suporte das políticas públicas é um fator que agrava uma situação já extremada de vulnerabilidade social que guarda relação direta com a vulnerabilidade penal da população negra, a qual resulta na fixação de "[...] uma imagem pública do delinquente com componentes de classe social, étnicos, etários, de gênero e estéticos" (ZAFFARONI et. al., 2003, p. 46). A vulnerabilidade penal é associada ao processo de criminalização dirigido a uma parcela da população, cumprindo tal processo a função de reprodução e de conservação social, pois "a punição de determinados comportamentos e sujeitos contribuiria para manter a escala social vertical e serviria de cobertura ideológica a comportamentos e sujeitos socialmente imunizados" (BARATTA, 2002, p. 15).

A vulnerabilidade social antes referida denuncia a (des)proteção das políticas públicas que, além de precárias, ainda estão marcadas pelo colonialismo que "reatualiza a captura da existência negra" (PASSOS, 2020, p. 118) e remetem a uma inversão: o Estado que deveria proteger, acaba promovendo violações de direitos que reafirmam a punição e o extermínio dos corpos matáveis e comportamentos negros (idem). Passos segue afirmando que o cuidado colonial "reatualiza a captura da existência negra" (idem), o que para Kilomba é a reafirmação do "racismo cotidiano não apenas como a reencenação de um passado colonial, mas também como uma realidade traumática, que tem sido negligenciada" (2019, p. 29). O racismo cotidiano que tenta reduzir a vida das mulheres negras a silenciamento e sofrimento, dor e morte, mas não consegue silenciar estas mulheres que enfrentam o risco e rompem com o indizível quando gritam o horror da guerra às drogas e a violência estatal, como diz bell hooks "exprimindo uma coragem da verdade" (2019, p. 13).

\section{O cuidado à saúde mental das mulheres negras em con- texto de guerra às drogas}

Para Fanon (2008), os homens e mulheres negras são colocados na "zona do não ser", em uma existência que se constrói a partir da construção de ser do homem branco. Ou conforme Kilomba, "nós nos tornamos a representação mental daquilo com o que o sujeito 
branco não quer parecer" (2019, p. 38). Este "não ser" é cotidianamente reificado pelo racismo que repercute na saúde mental das pessoas negras: "Que dor, estar presa/o nessa ordem colonial" (KILOMBA, 2019, p. 39). Uma ordem colonial que tenta alijar a população negra de seus direitos, e silenciar sua voz que denuncia.

Neste contexto os serviços de saúde são primordiais para auxiliar as mulheres negras a narrar estas opressões, constituindo espaços abertos para compartilhamentos de experiências, dores e lutas. Para além da medicação e escuta de sintomas, escuta do lugar desta mulher no mundo, do lugar que ela se pretende no mundo. O sofrimento pelo luto da morte pela violência policial precisa ser considerado em sua diferença, em seu testemunho da violência estatal e omissão da sociedade.

Tomemos por exemplo da importância da escuta às mulheres negras que vivem suas vidas em meio a guerra às drogas, o trabalho desenvolvido por um serviço de assistência social, que foi veiculado por um portal de notícias, onde a profissional do Centro de Referência em Assistência Social (CRAS) fala sobre o trabalho: "Com o atendimento psicossocial do serviço público, a proposta era que ela e outros parentes de vítimas de violência pudessem deixar de viver suas histórias em silêncio e na solidão" (CARNEIRO, 2018). A reportagem da BBC trata sobre um grupo que originalmente foi pensado para atender famílias, mas se formatou atendendo apenas mulheres, que além da dor de perder o filho também compartilham da criação de fiIhos sozinhas. Realidade no país em que mais de cinco milhões de pessoas não têm sequer o nome do pai na certidão de nascimento, em que $40 \%$ das famílias são chefiadas por mulheres - o que não significa a ausência masculina, já que em $34 \%$ havia a presença de um cônjuge (IPEA, 2017). A reportagem citada não informa o quesito raça/ cor das mulheres, mas em todas as fotos que mostram o grupo, sem identificar os rostos, podemos perceber que são mulheres negras, assim como nas fotos dos jovens que perderam a vida que compõe um mural - memória.

Ainda sobre este trabalho: "O objetivo era oferecer um serviço público de saúde e assistência social, incentivando políticas em prol da reparação psíquica de famílias que tiveram pessoas mortas por policiais, agentes estatais ou paraestatais" (CARNEIRO, 2018). Im- 
portante pensar que a promoção de saúde mental possa ocorrer em múltiplos espaços, não necessariamente em serviços de saúde tradicionais. Talvez a potência esteja justamente aí, um serviço de base territorial, que tem as mulheres e as famílias como público-alvo, abrindo uma acolhida em grupo para atentamente escutar uma demanda que se coloca ao serviço: a perda de jovens na guerra às drogas é uma realidade inscrita na sociedade. É preciso escutar como os efeitos dos confrontos da guerra impactam as pessoas, sobretudo as mulheres negras.

São raros os estudos que abordam a relação entre guerra às drogas e a saúde mental das mulheres negras. Esta intersecção entre guerra às drogas, racismo e saúde mental precisa estar inscrita no bojo das preocupações da saúde mental brasileira, já que encarceramento em massa (BORGES, 2018), o genocídio da juventude negra, a exposição cotidiana à violência da guerra, o convívio com a maquinaria bélica do Estado desde a infância, a guerra em tempos de paz, trazem prejuízos incalculáveis para as pessoas que vivem nas comunidades em que estas "batalhas" ocorrem, e em medidas diferentes para toda a sociedade. Não é possível pensar uma democracia com pessoas desviando de homens com fuzis, blindados passando em frente a escolas ou helicópteros e sons de tiros interrompendo o barulho de crianças brincando no recreio.

Um cuidado em saúde mental que não considere os efeitos dos sistemas de dominação sexista e patriarcal, de supremacia branca e capitalista na produção do cuidado, não considera a singularidade da existência desta mulher que passa pela sua existência como mulher negra, como aponta bell hooks (2019). Tratar os usuários dos serviços de saúde mental como um grupo homogêneo traz, entre outras consequências, a descaracterização dos sujeitos, provocando uma escuta parcial e, com isso, a redução de repertórios de cuidado que poderão ser ofertados a esta pessoa. Saber e considerar a pessoa com seus marcadores de existência, como mulher negra, periférica, jovem ou mulher negra, idosa e periférica, ajuda a ofertar uma escuta mais alinhada com a necessidade. Como escuta, estamos considerando o trabalho desenvolvido por todos os profissionais da saúde mental, inclusive o assistente social, que a partir de seu instrumental, alinhado à clínica de atenção psicossocial, poderá acolher e fazer 
uma escuta qualificada, no âmbito de sua qualificação para tal. Isso não guarda relação com a escuta que um profissional da psicologia poderá fazer, por exemplo, pois são objetivos e trabalhos diferentes. No âmbito da atenção psicossocial, a escuta é uma

[...] tecnologia leve que envolve relações do tipo diálogo, vínculo, acolhimento. Possibilita compreender o sofrimento psíquico a partir da pessoa, valoriza suas experiências e atenta para suas necessidades e diferentes aspectos que compõem seu cotidiano (MAYNART et al, 2014, p. 301).

A discussão sobre a guerra às drogas e os efeitos para a saúde mental das pessoas deve estar inscrita na agenda política e teórica da luta antimanicomial, e como pauta para o os serviços da Rede de Atenção Psicossocial (RAPS). Como já apontava Delgado, "os trabaIhos sobre a violência de Estado, especialmente sobre a tortura, violência policial, violência política, frequentam pouco o campo de produção no âmbito da saúde mental, embora sejam numerosos no âmbito dos Direitos Humanos, Política e História" (2012, p. 189).

A mulher negra é subjetivada de várias maneiras para a dedicação ao cuidado. Aprende desde criança, a importância de cuidar dos irmãos, da família, como um ensinamento das famílias negras, no entanto a estrutura social sexista e racista captura esta lógica do cuidado com seus, para esvaziar da reciprocidade desta ferramenta ancestral, que exige ser cuidada, que exige a atenção ao autocuidado, cria a fortaleza da mulher negra e nega a ela o direito ao cuidado, ao acolhimento, ao auxílio, à escuta de suas questões. Grada Kilomba reflete sobre esta questão a partir do relato de uma de suas entrevistadas para a sua pesquisa, diz que a ideia da "[...] supermulher de pele escura" carrega duas dimensões: "de um lado, como uma estratégia política para superar as representações negativas das mulheres negras no mundo branco. Mas, por outro lado, aprisiona as mulheres negras numa imagem idealizada que não nos permite manifestar as profundas feridas do racismo" (KILOMBA, 2019, p. 14).

Esta construção social colonialista, que também pode ser compreendida como parte da ferida colonial (KILOMBA, 2019; FANON, 2008) já obrigou muitas mulheres negras, na escravidão, a cuidar de famílias dos escravistas, e que do pós abolição até os dias de 
hoje coloca uma exigência no trabalho doméstico, para além das tarefas de limpeza, a abrir mão de suas vidas e famílias para cuidar de filhos de famílias brancas - que se soma ao cuidado com seus próprios filhos e muitas vezes netos. Num contínuo de trabalho onde: "O enorme espaço que o trabalho ocupa hoje na vida das mulheres negras reproduz um padrão estabelecido durante os primeiros anos de escravidão" (DAVIS, 2016, p. 17). Ainda sobre este padrão Passos refere que "a intersecção entre gênero, raça e classe vai levá-las a permanecer na execução do trabalho doméstico e de cuidados, não só como uma relação de extensão da esfera reprodutiva, mas estabelecida e demarcada pela colonialidade" (2020, p. 118).

As marcas persistentes da colonialidade à precarização do trabalho, à solidão no sustento e cuidado dos filhos, a violência, o assédio machista e à desvalorização do saber produzido, tudo isso têm sido negligenciado na atenção à saúde mental destas mulheres, reforçando uma produção discursiva que construiu e mantém a falácia da resistência da mulher negra, sob o falso elogioso manto de guerreira, que a tudo suporta.

\section{Mulher negra como sujeito de sua história}

É preciso romper com a narrativa única do negro enquanto sujeito em desigualdade de direitos, vítima de opressão e violência, e perseguir a dialética, reconhecendo as resistências e os protagonismos. Se a mulher negra sofre o impacto da guerra às drogas, como vítima do racismo, sexismo e a militarização do social materializada na política belicista de combate às drogas, também são elas que persistem no direito à memória, à reparação e à mudança na política.

A dor lancinante de perder um filho une as mães de maio ${ }^{1}$, um movimento que uniu mulheres mães que tiveram seus filhos assassinados em massacre, ocorrido em maio de 2006, onde 500 pessoas foram assassinadas. Mulheres que lutam por reparação do Estado e direito à memória. Grupo tem se ampliado e mobilizado mulheres

\footnotetext{
${ }^{1}$ Para saber mais sobre este movimento que tem sido inspiração para outros movimentos de familiares de pessoas vítimas da violência de Estado. Página do movimento: <http://maesdemaio.blogspot.com/>.
} 
em diferentes partes do país que tiveram seus filhos vitimados pela violência de Estado. São experiências singulares que se transformam em uma voz uníssona e potente para ultrapassar as barreiras do racismo institucional e buscar justiça por dentro do sistema criminal, que por vezes condenou seu filho, que lhes invisibiliza. A dor da perda é pessoal, mas também política. Pois como nos ensina Davis o pessoal é político (2018). Mulheres negras acadêmicas, pesquisadoras, ativistas e militantes também constroem uma nova iniciativa negra sobre drogas, uma coalizão por direitos e dezenas de movimentos nas cidades brasileiras. Também é Davis que nos lembra que "a história negra, seja aqui na América do Norte, seja na África, seja na Europa, sempre esteve impregnada de um espírito de resistência, um espírito ativista de protesto e transformação" (DAVIS, 2018, p. 105).

As mulheres negras podem estar como alvos desta guerra às drogas, mas são também escudo para seu povo, e principalmente são espadas na luta. Seguem ensinando que a luta é coletiva, que seus passos vêm de longe. Não como uma retórica, mas força motriz para vida no tempo presente, ainda que a história oficial sistematicamente apague as vitórias das lutas do povo negro, alçando vez ou outra uma figura heroica, como se fosse uma conquista individual. Os movimentos negros sempre inscreveram suas lutas e vitórias coletivas.

Estas mulheres negras afirmam em sua luta por justiça, por reparação, o direito à memória do real, à memória da vida dos seus filhos, como elas participaram, não como o colonialismo tenta reescrever após a sua morte. Uma vida jovem que foi interrompida pela violência da guerra às drogas, e sofre nova morte quando lhe foi atribuída uma pecha de traficante, ou ainda "baleado em conflito com a força policial", ou por "bala perdida." A luta é pela memória, pela restituição da "voz" aos mortos, o que ajuda a garantir o luto.

A história da colonização, do imperialismo, é um registro de traição, mentiras ou enganações. A exigência do que é real é uma exigência por reparação, transformação. Na resistência, o explorado, oprimido, trabalha para expor a falsa realidade - para reivindicar e recuperar a nós mesmos (HOOKS, 2019, p. 27).

Com relação a este tema, aprendemos com Davis que: "É fundamental resistir à representação da história como o trabalho de in- 
divíduos heroicos, de maneira que as pessoas reconheçam hoje seu potencial agência como parte de uma comunidade de luta sempre em expansão" (2018, p. 19). E segue afirmando que, embora tenha havido uma certa mobilidade social, trazendo como exemplo a eleição de Barack Obama nos EUA, "[...] a esmagadora maioria da população negra está sujeita ao racismo econômico, educacional e carcerário em uma proporção muito maior do que no período anterior a era dos direitos civis" (DAVIS, 2018, p. 20). A intelectual negra referese a sociedade estadunidense, mas se a partir de sua reflexão analisarmos a sociedade brasileira veremos que os negros e negras no Brasil, mesmo com políticas afirmativas como as cotas raciais em universidades, estão em condições de trabalho, renda, saúde e moradia desfavoráveis em relação aos homens e mulheres brancas. Sobre estas condições de vida, Veiga nos auxilia com um resumo sobre os efeitos do colonialismo,

[...] que se inaugura com a abertura do país para a entrada de imigrantes europeus no século XIX e que se desdobra até os dias de hoje nos quais: a cada 23 minutos um jovem negro é assassinado; a expectativa de vida dos negros é seis anos menor do que a dos brancos; $75 \%$ da população mais pobre é negra; a renda per capita de famílias negras é $200 \%$ menor do que a renda de famílias brancas; apesar de ser mais de $54 \%$ da população nacional, negros são minoria no congresso, nas universidades, na televisão e em todos os espaços de poder e prestígio da sociedade (VEIGA, 2019, p. 245).

Podemos inferir que políticas públicas progressistas sozinhas não são capazes de romper com a hierarquia racial no Brasil, podendo inclusive reproduzir o racismo estrutural e o colonialismo em suas instituições. Dito isso, podemos pensar que ainda que a reforma manicomial tenha produzido importantes mudanças no cuidado, provocando uma torção na lógica manicomial e construindo um cuidado em liberdade, a partir da criação de uma práxis emancipadora, atenta aos direitos humanos e à autonomia das pessoas, não foi capaz de trazer o combate do colonialismo e o racismo para o cerne da proposta. Assim como Davis aponta para a "[...] incompletude das lutas planetárias por igualdade, justiça e liberdade" (2018, p. 81), entende- 
mos como incompleta todas as conquistas nas políticas sociais, incluindo a reforma antimanicomial.

Neste sentido, faz-se necessário que nossa luta seja por uma reforma "antimanicolonial" (GOMES, 2019), por uma Rede de Atenção Psicossocial, que atenda os princípios do SUS, que preconize o cuidado em liberdade, sem segregação e sem manicômios e em luta para sua expansão, para que seja capaz de atender aqueles e aquelas que ainda não conseguiram acesso aos serviços substitutivos, para os quais as instituições totalizantes seja sob o manto da saúde seja sob a batuta do sistema penal, são o destino. Pois que, não basta ser antimanicomial, é preciso ser "antimanicolonial"!

\section{"A gente combinamos de não morrer" - ou Considerações finais}

A frase que dá título às nossas considerações finais foi extraída do texto de Olhos D'água de Conceição Evaristo, e tem sido evocada para marcar poeticamente a resistência das mulheres negras à ao racismo e a política de morte que faz com que o assassinato dos corpos negros seja sistemático, não só a morte por bala, mas o encarceramento do corpo, a negação dos direitos, o silenciamento das histórias e a negação da memória. Viver em comunidades em que carros blindados adentram as ruelas em qualquer dia e horário, em que o som do helicóptero pode competir com o som da celebração da vida que comemora mais um ano, o ir e vir do trabalho com medo de operações policiais, os tiros, o medo. Por vezes uma existência de medo e luto, ora por um irmão, ora por um filho, ora por um vizinho. Comunidades inteiras experienciam o luto, de uma morte que não pode ser chorada, pois a morte se segue à luta por justiça e por preservar a memória do ente querido, como um ser humano. A pandemia agrega ainda a impossibilidade da união, dos atos fúnebres, que auxiliam a suportar a dor da partida e dão dignidade a despedida. A guerra às drogas desumaniza as pessoas que tombam sob alcunha se traficante. Não é possível dimensionar o trauma destas experiências, o adoecimento que pode se seguir ao evento traumático. Mas não só a ele, 
uma insistência traumatizante, um luto constante, uma luta incessante.

Antes da violência da bala, do ver e saber do corpo no chão, da ausência do filho, do afeto, do amor, da vida que Ihe continua, muito antes o trauma de viver com a possibilidade que isso aconteça. A história de perda e de cárcere da outra mãe, filha e esposa que te assombra, como uma experiência que te espreita. A dor do luto que se torna o medo do luto, este como uma experiência coletiva. Uma repetição incessante, lutos que se somam e o medo nunca finda, ao contrário se presentifica, ainda que vivido na experiência de outrem.

Será que os serviços de saúde mental sabem escutar este trauma? Será que este medo acha lugar para se colocar em palavras e assim, não adoecer o corpo que teme? Ainda que possa ser narrado em primeira pessoa, é escutado como uma experiência marcada pela intersecção da raça, classe e gênero? Como uma ferida colonial que insiste em sangrar, machucada continuamente pelo racismo e a política de morte racista.

Ainda, assim as mulheres negras existem na insistência pedagógica de lutar pela vida. Produzindo literatura, ciência, luta política e transformação social, estas mulheres rompem com a máscara invisível do silenciamento e transformam a sua própria história e a história oficial brasileira.

$\mathrm{Na}$ pandemia a gestão organizada da crise sanitária e social que chegou nas periferias foi feita em grande medida pela população organizada. Foram os coletivos, com grande protagonismo das muIheres negras, que organizaram o cuidado em saúde em comunidades; articularam uma colisão por direitos para denunciar o genocídio da população negra, construíram frentes de enfrentamento à fome. A luta das mulheres negras contra o racismo e pela vida sempre existiu, se transformou e intensificou na pandemia de COVID-19. "As mulheres negras estão enfrentando o racismo durante a pandemia, ampliando as estratégias já utilizadas no combate ao racismo historicamente no Brasil. Nós estamos atuando com diferentes ações e fren- 
tes de luta", afirmou Mônica Oliveira para a reportagem da ONU Mulheres. $^{2}$

Os serviços de saúde poderiam atuar como espaço seguro para que estas narrativas de vida em luta, circulem livremente e encontrem acolhimento para que se possa construir uma existência com menos sofrimento e com a garantia de cuidado em saúde mental, e eco para questionar e buscar transformar a política proibicionista que encarcera e mata. Não há sociedade verdadeiramente democrática com o racismo, sexismo e o capitalismo hierarquizadores das relações sociais.

\section{Referências}

BARATTA. Criminologia crítica e crítica do direito penal: introdução à sociologia do direito penal. 3. ed. Rio de Janeiro: Revan, 2002.

BATISTA, A. et al. Análise socioeconômica da taxa de letalidade da COVID-19 no Brasil. Núcleo de Operações e Inteligência em Saúde (NOIS). Rio de Janeiro: PUC-Rio, 2020.

BORGES, J. O que é encarceramento em massa? Belo Horizonte: Letramento; Justificando, 2018.

BRASIL. Levantamento de informações penitenciárias INFOPEN MuIheres. Brasília: Ministério da Justiça, 2018.

BUTLER, J. Vida precária. Contemporânea, São Carlos, n. 1 p. 13-33, jan.-jun., 2011.

CARNEIRO, H. As necessidades humanas e o proibicionismo das drogas no século XX. Revista do Instituto de Estudos Socialistas, São Paulo, n. 6, p. 115-128, 2002.

CARNEIRO, J. D. Unidas pela dor: mães que perderam filhos para a violência encontram amparo em grupo no RJ. BBC Brasil, Rio de Janei-

\footnotetext{
${ }^{2}$ Monica Oliveira, coordenadora da Rede de Mulheres Negras do Nordeste e integrante do Grupo Assessor da Sociedade Civil Brasil da ONU Mulheres, em entrevista para ONU Mulheres. Disponível em: <http://www.onumulheres.org.br/noticias/mulheres-negras-agem-paraenfrentar-o-racismo-na-pandemia-COVID-19-e-garantir-direitos-da-populacao-negra-nonovo-normal/>. Acesso em: 14 set. 2020.
} 
ro, 2018. Disponível em: <https://www.bbc.com/portuguese/amp/ brasil-43915337>. Acesso em: 10 set. 2020.

DAVIS, A. Mulheres, raça e classe. São Paulo: Boitempo, 2016.

A liberdade é uma luta constante. São Paulo: Boitempo, 2018.

DELGADO, P. G. G. Violência e saúde mental: os termos do debate. 0 Social em Questão, Rio de Janeiro, ano 15, n. 28; p. 187-198, 2012. Disponível em: <http://osocialemquestao.ser.puc-rio.br/media/9artigo.pdf $>$. Acesso em: 08 set. 2020.

ESCOHOTADO, A. Historia general de las drogas: incluyendo el apéndice fenomenologia de las drogas. Madrid: Espasa Calpe, 2008.

EVARISTO, C. Olhos d'água. Rio de Janeiro: Pallas Editora, 2016.

FANON, F. Peles negras, máscaras brancas. Salvador: Editora EdUFBA, 2008.

FERREIRA, S.; PORTO, D. Mistanásia $\times$ Qualidade de vida. Revista Bioética, v. 27, no 2, p. 191-195. Brasília, 2019. Disponível em: <http://www.scielo.br/scielo.php?script=sci_arttext\&pid=S198380422019000200191\&lng=en\&nrm=iso>. Acesso em: 15 set. 2020.

FERRUGEM, D. Guerra às drogas e a manutenção da hierarquia racial. Belo Horizonte: Letramento, 2019.

GOMES, B. S. Encontros antimanicoloniais nas trilhas desformativas. Trabalho de Conclusão de Curso (Especialização em Saúde Mental Coletiva) - Programa de Residência Integrada Multiprofissional em Saúde Mental Coletiva. 2019. Universidade Federal do Rio Grande do Sul, Porto Alegre, 2019.

GORTÁZAR, N. G. Mortes em operações policiais aumentam no Brasil, apesar da quarentena. El País online. São Paulo, 2 de junho de 2020. Disponível em: <https://brasil.elpais.com/brasil/2020-06-02/mortesem-operacoes-policiais-aumentam-no-brasil-apesar-da-quarentena.html>. Acesso em: 14 set. 2020.

GALTUNG, J. Violence, peace, and peace research. Journal of Peace Research, vol. 3, no 6, p. 167-191, 1969. Disponível em: <https:// 
www.jstor.org/stable/422690?seq=1\#page_scan_tab_contents $>$. Acesso em: 15 set. 2020.

GERSHENSON, B.; FERREIRA, G. G.; AVILA, L. de F.; JACQUES, C. O. Juventudes encerradas: extermínio e aprisionamento segundo opressões de classe, raça e gênero. Argumentum, Vitória, v. 9, n. 1, p. 119133, 2017. Disponível em: <https://bit.ly/2Qx7351>. Acesso em: 11 nov. 2019.

GONZALEZ, L.; HASENBALG, C. A. Lugar de negro. Editora Marco Zero, 1982

HART, C. L. Um preço muito alto. A jornada de um neurocientista que desafia nossa visão sobre as drogas. Rio de Janeiro: Zahar, 2014.

HOOKS, B. Erguer a voz: pensar como feminista, pensar como negra. São Paulo: Elefante, 2019.

INSTITUTO DE PESQUISA ECONÔMICA APLICADA - IPEA. Retrato das desigualdades de gênero e raça - 1995 a 2015. Brasília: IPEA, 2017. < https://www.ipea.gov.br/portal/index.php?

option=com_content $\&$ view=article \&id=29526\&catid=10\&ltemid=9>. Acesso em: 10 ago. 2020.

KILOMBA, G. Memórias da plantação: episódios de racismo cotidiano. Rio de Janeiro: Cobogó, 2019.

MAYNART, W. C. et al. A escuta qualificada e o acolhimento na atenção psicossocial. In: Acta Paulista de Enfermagem, São Paulo, v. 27, n. 4, p 300-303, 2014. Disponível em: <http://www.scielo.br/pdf/ ape/v27n4/1982-0194-ape-027-004-0300.pdf>. Acesso em: 25 jan. 2020.

MORRISON, T. Racismo e fascismo \& o corpo escravizado e o corpo negro. MORRISON, T. Fonte da Autoestima. São Paulo: Companhia das Letras, 2019.

NASCIMENTO, A. O genocídio do negro brasileiro. Processo de um racismo mascarado. 2. ed. São Paulo: Perspectiva, 2017.

PASSOS, R. G. Mulheres negras, sofrimento e cuidado colonial. In: Em Pauta - teoria social e realidade contemporânea: Revista da FSS/ UERJ, no 45, p. 116 - 129. Rio de Janeiro, 2020. Disponível em: 
<https://www.e-publicacoes.uerj.br/index.php/revistaempauta/article/view/47219>. Acesso em: 14 set. 2020.

SAAD, L. G. "Fumo de negro": a criminalização da maconha no Brasil (1890-1932). 2013. 139 f. Dissertação (Mestrado em História) - Programa de Pós Graduação em História, Faculdade de Filosofia e Ciências Humanas, Universidade Federal da Bahia, Salvador, 2013.

SIMÕES, J. A. Prefácio. In: LABATE, B. C. et al. (Org.) Drogas e cultura: novas perspectivas. Salvador: EdUFBA, 2008.

VASCONCELOS, C. Com 812 mil pessoas presas, Brasil mantém a terceira maior população carcerária do mundo. Ponte Jornalismo, São Paulo, 19 de julho de 2019. Disponível em: <https://ponte.org/com812-mil-pessoas-presas-brasil-mantem-a-terceira-maior-populacaocarceraria-do-mundo/ >. Acesso: 14 set. 2020.

VEIGA, L. M. Descolonizar a Psicologia: considerações a uma psicologia preta. CEERT, São Paulo, 28 de novembro de 2017. Disponível em: $<$ https://ceert.org.br/noticias/direitos-humanos/20238/descolonizara-psicologia-consideracoes-a-uma-psicologia-preta>. Acesso em: 10 jan. 2020.

. Descolonizando a psicologia: notas para uma psicologia preta. Fractal: Revista de Psicologia, Niterói, v. 31, n. esp., p. 244-248, set. 2019. Disponível em: <http://periodicos.uff.br/fractal/article/view/ 29000/20061>. Acesso em: 10 jan. 2020.

WERNECK, J. Um pacto pela vida dos jovens negros. Anistia Internacional Brasil. Disponível em: <https://anistia.org.br/um-pacto-pelavida-dos-jovens-negros/>. Acesso em: 14 set. 2020.

ZAFFARONI, E. R. et al. Direito penal brasileiro. v. 1, 2. ed. Rio de Janeiro: Revan, 2003. 